\title{
Role of Systemic T-cells and Histopathological Aspects after Subcutaneous Implantation of Various Carbon Nanotubes in Mice
}

Shozo Koyama ${ }^{1}$, Morinobu Endo ${ }^{2, *}$, Yoong-Ahm Kim ${ }^{2}$, Takuya Hayashi ${ }^{2}$, Takashi Yanagisawa $^{2}$, Kazumasa Osaka ${ }^{1}$, Haruhide Koyama ${ }^{1}$ and Naomi Kuroiwa ${ }^{1}$

${ }^{1}$ Department of Integrative Physiology and Bio-System Control, School of Medicine, Shinshu University, Matsumoto 390-8621, Japan

${ }^{2}$ Department of Electrical and Electronic Engineering, Faculty of Engineering, Shinshu University, Nagano 380-8553, Japan

\section{Abstract}

We have evaluated the biological responses to four different types of carbon nanotubes (CNTs), by measuring $\mathrm{CD}^{+}$and $\mathrm{CD}^{+}$T-cells in peripheral blood, and by the histopathological study on tissues surrounding subcutaneously implanted CNTs for up to 3 months. All mice survived, and no large changes in their weights were observed within our experimental period. After one week, only single walled carbon nanotubes (SWNTs) activated major histocompatibility complex (MHC) class I pathway of antigen-antibody response system (higher $\mathrm{CD} 4^{+} / \mathrm{CD} 8^{+}$value), resulting in the appearance of an edematous aspect. After two weeks, significantly high values in $\mathrm{CD} 4^{+}$ and $\mathrm{CD}^{+} / \mathrm{CD}^{+}$without change in $\mathrm{CD}^{+}$signified an activated MHC class II for all samples. It is worth noting that the toxicological response of CNTs was absolutely lower than that of asbestos. As a result, we envisaged that our result (relatively low toxicity of CNTs) will spur the mass-production, as well widespread application of CNTs in the 
near future.

*Corresponding author: M. Endo, Tel: +81-26-269-5201, Email: endo@endomoribu.shinshu-u.ac.jp

Keywords: Carbon Nanotubes, Chemical vapor deposition, Optical microscopy, Bioactivity

\section{Introduction}

Much attention has been paid on the tiny but interesting $s p^{2}$-based carbon nanotubes (CNTs), due to their small size and extraordinary physicochemical properties which make them useful in a wide range of applications from nanocomposites, sensor, electronic nano-device, electrochemical system to medical device such as micro-catheter [1-4]. These days, large quantity of carbon nanotubes is available due to the establishment of well-developed chemical vapor deposition (CVD) method, especially using the floating reactant method $[5,6]$. In this sense, the toxicology of these CNTs has to be evaluated under environmental and occupational exposure including biocompatibility. It is expected that their intrinsic features, derived from the nano-scale and high aspect ratio (above 100), gives rise to different biological effects compared to micro- and macro materials, even though conventional carbon materials have extremely high level of biocompatibility as used for artificial heart valves.

Unfortunately, there have been limited studies available on the toxicology of nano-sized materials including CNTs, as compared with that of asbestos [7, 8]. Recently published studies on pulmonary toxicity of CNTs proved that inhaled CNTs induced the 
formation of epithelial granulomas and inflammation $[9,10]$. Furthermore, it is suggested that some nanoparticles might be toxic to human keratinocytes [11]. When considering application of CNTs especially in biomedical engineering and in vivo chemistry, their biocompatibility have to be evaluated clearly because CNTs exhibited cytotoxicity to human keratinocyte cells [11, 12], have inhibited the growth of embryonic rat-brain neuron cells [13] and have induced formation of lung granulomas in mice $[9,10,14]$. Therefore, it is essential that their biocompatibility and also their potential toxicity be investigated systematically. Here, we report time-dependent changes in $\mathrm{CD}^{+}$and $\mathrm{CD} 8^{+}$T-cells, and also pathological differences between four different types of CNTs ranging from single-walled carbon nanotubes (SWNTs), two types of multi-walled carbon nanotubes with different diameters (MWNTs-I $=$ ca. $20 \mathrm{~nm}$ in diameter, MWNTs-II = ca. $80 \mathrm{~nm}$ in diameter) to cup-stacked type carbon nanotubes (CSNTs) after the subcutaneous implantation for 3 months in mice $[8,15]$. Our basic study will contribute to the intensified research and development of CNTs not only in engineering fields but also in medical and biology areas under suitable handling of CNTs.

\section{Experimental}

\subsection{CNT Materials}

High purity SWNTs were obtained through a combination of catalytic CVD method and optimized purification method [16]. They are self-assembled into a bundle structure (Figure 1(a)) while a detailed high-resolution transmission electron microscope (HR-TEM) study revealed that their diameters are generally in the range from 0.8 to 2.0 nm (Figure 1 (b)). Two types of MWNTs with different diameters ranges ( $\mathrm{I}=20-70 \mathrm{~nm}$ 
and $\mathrm{II}=50-150 \mathrm{~nm}$ ) were chosen as samples, which were obtained by catalytic CVD method by controlling reaction conditions judiciously (e.g., reaction temperature, the amount of organic-metallic compounds, flow-rate etc.) (Figure 1 (c)-(f)) $[3,17,18]$. Then as-grown MWNTs were thermally treated up to $2800^{\circ} \mathrm{C}$ in argon atmosphere using a graphite furnace in order to improve structural integrity and also remove polyaromatic hydrocarbons and iron compounds of the as prepared samples. CSNTs were synthesized by a floating reactant method using iron as a catalyst, hydrogen sulfide as a co-catalyst, and natural gas as a carbon feedstock in a continuous process [19]. The obtained tubes with unique morphology (stacked truncated cones in Fig. $1(\mathrm{~g})$ and $(\mathrm{h})$ ) exhibited higher chemical reactivity due to a large portion of open edges at the outer and inner surface. Basic properties of all nanotubes used in this study are summarized in Table 1. Metal iron, which is the essential component for nanotube growth, has to be removed completely because metal-related toxicity was proved [20-22]. Therefore, thermal treatment process (up to $2800^{\circ} \mathrm{C}$ ) will be very helpful for getting highly purified carbon nanotubes by evaporating metal particles contained in carbon nanotubes (see Table 1).

All samples were sterilized by formaldehyde gas exposure for 24 hours. After vaporizing the gas for more than 24 hours at the room temperature, those samples were implanted into the subcutaneous tissue below the back skin.

\subsection{Animals, Surgical Implantation and Sampling}

One hundred eighty female BALB/c mice aged 5 weeks were purchased from SLC (Japan). All animals were bred in the pathogen-free animal facility (at School of Medicine, Shinshu University). Experiment was started at aged 6 weeks after the stabilization in the facility for 1 week. Those animals were divided into 5 groups: 
control, SWNTs, MWNTs-I, MWNTs-II and CSNTs. 30 animals were allocated to each group. These allocated animals were divided into 6 subgroups, which were sacrificed for sampling of blood from the heart and tissue at one, 2, 3 weeks, one month, 2 months and 3 months post-implantation. The back skin of each animal was incised about $1 \mathrm{~cm}$ under fluothane anesthesia and each sample of $2 \mathrm{mg}$ was embedded subcutaneously. Then, the incised wound was sutured. As the control, $2 \mathrm{ml}$ of the physiological saline was used. When the time was achieved to the expected date of sampling blood and tissue, each animal was sacrificed under the deep anesthesia of fluothane. Blood was sampled by the cardiac puncture for flowcytometry measurement, and tissue of skin including muscle layer was removed for pathological examination.

\subsection{Flowcytometry}

Sampled blood was stained by antibodies of $\mathrm{CD} 4^{+}$antibody and $\mathrm{CD} 8^{+}$antibody (BD Bioscience Pharmingen, USA) for sorting $\mathrm{T}$ lymphocytes by a flow cytometer (FACS Clibur, Becton Dickinson, USA). Those stained immune cells were analyzed using CeIIQuest software (Becton Dickinson).

\subsection{Histology and immunohistochemistry}

For conventional histology, tissues were taken immediately after sacrifice, fixed in $70 \%$ ethanol, embedded in paraffin, cut into $5 \mu \mathrm{m}$ sections, and stained with hematoxylin and eosin. In addition, using one of the serial sections, endogenous peroxidase was blocked with $3 \% \mathrm{H}_{2} \mathrm{O}_{2}$ for $10 \mathrm{~min}$, and incubated for $60 \mathrm{~min}$ at room temperature with anti-mouse CD45R antibody (BD Bioscience Pharmingen, USA) and anti-mouse Mac-3 antibody (BD Bioscience Pharmingen, USA ). The slides were 
washed and a biotinylated polyclonal rat-IgG1/2a antibody (BD Bioscience Pharmingen, USA) was applied. After three further PBS washes, the section was incubated with peroxidase-conjugated streptavidin (BD Bioscience Pharmingen, USA) for 60min, was colorized with diamino-benzidine and counterstained with hematoxylin.

\subsection{Statistical analysis}

Significant differences were assessed using the two-tailed student's t-test at $\mathrm{P}<0.05$. Data were shown mean \pm SE.

\section{Experimental Results}

\subsection{Body weight}

All animals survived the test period. In addition, no large changes in body weight of animals for all groups versus control indicate a good standard development within our experimental time (up to 3 months) (Figure 2). As a comparative standard (control), values of $\mathrm{CD}^{+}$T-cells at $1,2,3$ weeks, 1 month, 2 months and 3 months post-implantation were $30.7 \pm 4.9 \%, 36.3 \pm 2.2 \%, 27.2 \pm 3.3 \%, 32.4 \pm 0.6 \%, 40.9 \pm 2.31 \%$ and $28.9 \pm 3.9 \%$ while values of $\mathrm{CD}^{+} \mathrm{T}$-cells at same time were $11.1 \pm 0.9 \%, 11.6 \pm 0.4 \%$, $16.3 \pm 2.9 \%, 10.1 \pm 0.14 \%, 12.3 \pm 1.4 \%$ and $7.4 \pm 0.6 \%$ respectively.

\subsection{Single walled carbon nanotubes}

Figure 3 shows the time-dependent changes of peripheral T-cells after the subcutaneous implantation of SWNTs. CD4 ${ }^{+}$of SWNT-implanted T cells versus control is significantly high at 2 weeks $(46.3 \pm 2.2 \%)$ and 3 months $(44.2 \pm 3.9 \%)$ post-implantation (Fig. 3 (a)). Furthermore, a significant decrease in $\mathrm{CD} 8^{+}$T-cells for 
SWNTs versus control was observed at one week $(7.5 \pm 0.1 \%)$ and 3 weeks $(11.0 \pm$ 0.7\%) post-implantation (Fig. 3 (b)). Therefore, it is noteworthy that SWNTs-implanted tissue T-cells exhibited relatively high values of $\mathrm{CD}^{+} / \mathrm{CD}^{+}$at 1 and 3 weeks $(3.6 \pm 0.3$ and $2.8 \pm 0.3$ respectively) post-implantation than that of control (Fig. 3 (c)). To confirm the change in the peripheral T-cells after SWNTs subcutaneous implantation, histopathological study for samples from 1 week to 1 month were carried out (Figure 4). At 1 week, a loose space was evidently observed between SWNTs and the tissue, indicating an existence of exudative fluid (edema). This space became smaller at 2 weeks post-implantation. However, cell infiltration by SWNTs occurred at this period. We observed granulomatous tissue with cell infiltration at 3 weeks post-implantation. This granuloma encapsulating agglomerates of SWNTs became tight at 1 month post-implantation. Thus, there was no evidence for cell infiltration into aggregated SWNTs, possibly due to tightly packed structure of SWNTs themselves.

\subsection{Multi-walled carbon nanotubes-I}

Values of $\mathrm{CD}^{+}$T-cells decrease significantly at 1 week $(17.8 \pm 4.9 \%)$ and increase highly at 2 weeks $(48.6 \pm 2.2 \%$ ) post-implantation (Fig. 5 (a)). Also, a significant decrease in $\mathrm{CD}^{+}$T-cells versus control was observed at 1 week $(6.9 \pm 0.5 \%)$ and 3 weeks $(8.6 \pm 0.7 \%)$ post-implantation (Fig. 5 (b)). Therefore, relatively higher values of $\mathrm{CD}^{+} / \mathrm{CD}^{+}$were observed only at 2 weeks $(3.8 \pm 0.1)$ post-implantations (Fig. 5 (c)). As shown in Figure 6, MWNTs have induced cell infiltration without an edemoutous aspect at 1 week post-implantation. A granulomatous tissue becomes compact and tight between agglomerates of nanotubes with time.

Finally, several particles were phagocytozed over 3 weeks post-implantation. 


\subsection{Multi-walled carbon nanotubes-II}

Relatively low values of $\mathrm{CD}^{+} \mathrm{T}$-cells are observed at 1 week $(16.4 \pm 0.8 \%)$ and 3 weeks $(13.7 \pm 1.9 \%)$ while high value of $\mathrm{CD}^{+}$was found at 2 weeks $(53.5 \pm 0.8 \%)$ post-implantation (Fig. 7 (a)). Also, we observed significant decreases in CD8 ${ }^{+}$T-cells versus control at 1 week $(8.2 \pm 0.8 \%)$ and 3 weeks $(7.8 \pm 0.9 \%)$ post-implantation. In addition, it is interesting to note that a significant increase of $\mathrm{CD} 8^{+} \mathrm{T}$-cells occurred at 3 months post-implantation (Fig. 7 (b)). Therefore, values of $\mathrm{CD}^{+} / \mathrm{CD} 8^{+}$are quite lower $(2.1 \pm 0.2)$ than control. However, a significantly high level of $\mathrm{CD}^{+} / \mathrm{CD} 8^{+}$in this sample was observed only at 2 weeks $(4.7 \pm 0.3)$ post-implantation (Fig. 7 (c)). From histopathological study of MWNTs-II implanted tissue, we observed a slight cell infiltration with less exudation at one week post-implantation and as well a slight formation of granuloma. The cell infiltration is closely attached to the implanted mass peripherally at 2 weeks post-implantation. However, even at one month, cell infiltration did not occur in the central space of the mass. However, the mass was sealed tightly with a granulomatous tissue as shown in Figure 8.

\subsection{Cup-stacked type carbon nanotubes}

In this group, changes in $\mathrm{CD}^{+} \mathrm{T}$-cells are high at one $(18.2 \pm 1.4 \%)$, and almost double at 2 weeks $(53.5 \pm 0.8 \%)$ and 3 months $(40.1 \pm 3.2 \%)$ post-implantations vs. control (Fig. 9 (a)). Besides, abrupt decreases in $\mathrm{CD}^{+}$T-cells vs. control were found at 1 week $(6.6 \pm 0.6 \%)$ and 3 weeks $(6.6 \pm 0.9 \%)$ post-implantation (Fig. 9 (b)). Therefore, we obtained high values of $\mathrm{CD} 4^{+} / \mathrm{CD}^{+}$at 2 weeks $(4.2 \pm 0.1), 3$ weeks $(3.3 \pm 0.3)$ and 3 months (4.8 \pm 0.5$)$ post-implantations (Fig. 9 (c)). As shown in Figure 10, this tube 
caused slight cell infiltration with an edemoutous aspect at early stage of 1 week post-implantation. When time has passed, a granulomatous tissue became compact and tight between agglomerates of tubes. It is noteworthy that highly dispersed tubes (that look like a spider's web) induced lower cell infiltration than that of aggregated tubes.

3.6 Comparison of Immunohistochemical Investigation with Mac-3 antibody and CD45R antibody

Figure 11 shows an immunohistochemical aspect of the tissue section for macrophages with anti-murine Mac-3 antibody 1 week after CNTs-implantation. More positive cells for Mac-3 were observed in MWNTs-II and CSNTs than in SWNTs and MWNTs-I. Sequential order for the positive intensity was as following; MWNTs-II = CSNTs $>$ MWNTs-I > SWNTs. Figure 12 exhibits immunohistochemical aspect 1 month after implantation using antibody of Mac-3. It is evident that larger numbers of positive cells were found around the material of SWNTs. The granulomatous tissue in SWNTs consisted partly of component of macrophages, and we did not see phagocytic cells. However, positive cells for Mac-3 on granulomatous tissue in MWNTs-I (panel C) were lower than in SWNTs. We can observe positive cells in the narrow space of self-aggregated massive materials. It is very interesting to note that phagocytotic aspects were observed in MWNTs-II (see Fig. 12 (d)) and CSNTs (see Fig. 12 (e)).

\subsection{Comparison of granuloma formation at the late stage of 3 months post-implantation}

Differences in granuloma aspect and arrangement of implanted CNTs at the final stage of this protocol (three months post-implantation) were illustrated in Figure 13. Although granuloma was completed in all samples at 3 months post-implantation, there 
was a difference in wall thickness attached with the material. Especially, the wall thickness in SWNTs was larger than the others. However, the degree of cell invasion into aggregated CNTs was increased in the following order; CSNTs, MWNTs-II, MWNTs-I. In addition, a loose boundary exists between the granuloma, and the implanted material was especially found in MWNTs-I. No material was found at the spleen, liver, kidney, lung, heart and cerebral cortex in all animals at their autopsy.

\section{Discussion}

In this study, by using peripheral T-cell in combination with histological study, we have investigated the biological response to four types of carbon nanotubes. CNTs used here gave rise to several characteristic time-dependent changes in $\mathrm{CD} 4^{+}-$and $\mathrm{CD} 8^{+}$ T-cells. In addition, these changes are strongly dependent upon the post-implantation time. From these experimental results, when evaluating toxicology of CNTs, we should consider several important facts, such as the physiochemical properties of materials, self-aggregated size and an exposed period in vivo. Thus, the study on peripheral T-cells might be the simple and useful technique to evaluate the biocompatibility of CNTs, and to detect the onset of occupational diseases when workers in industries are accidentally exposed or inhaled CNTs.

From Table 2, SWNTs induced major histocompatibility complex (MHC) class I pathway of antigen-antibody response system at 1 week. Therefore, tissue samples in SWNTs exhibited an edematous aspect and low cell infiltration than other CNTs. At 2 weeks, MHC class II was activated. At 3 weeks, SWNTs showed an activation of MHC class II pathway. MWNTs-I and CSNTs inhibited MHC class I. However, MWNTs-II inhibited both of MHC class I and class II pathways. A contribution of macrophage on 
the tissue reaction to CNTs used here may depend on those different patterns of $\mathrm{MCH}$ post-implantation. Generally, it is well known that foreign body rejection is T-cell-dependent with both MHC class II restricted $\mathrm{CD}^{+}$and $\mathrm{MHC}$ class I restricted $\mathrm{CD}^{+}$T-cells being implicated in the process [23, 24]. Rosenberg et al [23] demonstrated that nude mice reconstituted with either $\mathrm{CD} 4^{+}$or $\mathrm{CD} 8^{+} \mathrm{T}$-cells alone were capable of rejecting a fully $\mathrm{MHC}$ mismatched skin graft as foreign bodies. However, with a lesser degree of antigenic mismatch, grafts as foreign bodies were rejected more rapidly if $\mathrm{CD}^{+}$and $\mathrm{CD}^{+}$populations were both present. They also demonstrated the importance of MHC restriction: class II disparate grafts as the foreign body being rejected most efficiently by $\mathrm{CD} 4^{+}$T-cells and class I disparate foreign body most efficiently by $\mathrm{CD}^{+}$T-cells [24]. Additionally, it is known that both helper and cytotoxic function are required for the occurrence of foreign body rejection. Although these two functions were most often affected by helper $\mathrm{CD}^{+}$T-cell and cytotoxic $\mathrm{CD}^{+} \mathrm{T}$ collaboration, single $\mathrm{CD}^{+}$T-cell subsets, which demonstrated in vitro helper and cytotoxic function, were able to reject foreign body autonomously. Furthermore, the MHC class I antigen processing pathway has largely evolved to permit the immune system to sample intracellular/cytosolic compartments for evidence of intracellular dysfunction. This alternate MHC class I processing pathway seems to be an essential mechanism for activating T-cells. In addition, $\mathrm{CD} 4^{+} \mathrm{T}$ cells can be divided into subsets based on the expression of the cell surface antigen CD45. Positive CD45 cells provide B cell help and induce $\mathrm{CD}^{+}$killer cells [25]. In this study, it is shown that CNTs as foreign bodies induce a different pattern of those pathways for antigenic mismatch until 3 weeks post-implantation in mice. Thus, a careful evaluation of toxic effects of CNTs considering the temporal factor is needed. The other findings in this study, the antigenic 
mismatch becomes less when the time-passed above one month post-implantation, indicating an establishment of granuloma formation. However, an involvement of T-cell subsets on CNTs in vivo remains unclear from the present study because of the negative finding of CD45R. Future study is needed to clarify more biological responses to CNTs using different bio-markers such as cytokines and chemokines.

There are limited reports concerning on toxic effects of CNTs because nanomaterial engineering such as CNTs is a new scientific field. Thus, toxicological evidences are badly needed for preventing a risk of occupational disorders in workers and promoting an application of CNTs in the field of biology such as medicine. Recently, Lam et al [9] reported the pulmonary toxicity of three kinds of CNTs in mice, using intratracheal instillation; SWNTs induced pulmonary disturbances such as inflammations of broncho-alveolar airway and formation of granuloma in mice. As a model of pulmonary toxicology on CNTs, Warheit et al [10] showed acute lung toxicity of intratracheally instilled SWNTs in rats, evaluated by histopathological investigation at $24 \mathrm{~h}, 1$ week, 1 month, and 3 months post-instillation. They showed a high mortality after exposures of SWNT, resulting from mechanical obstruction of the upper airways within 24 hours. Even survived animals showed transient inflammatory and cell injury due to a foreign tissue body reaction. However, the degree and process of granuloma formation induced by SWNTs were inconsistent with their parameters such as thoracheal levage and cell proliferation.

Interestingly, in our protocol demonstrated here, a mortality of animals was zero, and no chronological changes of body weight were observed among CNTs-implanted animals versus control over 3 months post-implantation. Time-dependent changes in peripheral T-cells, which involved into CNTs in situ, were well correlated with a 
processing phase of granuloma formation. Thus, the finding of pulmonary multi-focal granuloma reported by Warheit et al [10] may be more clarified by joining with measurement of T-cells described here. There are several reports about toxic effects of CNTs, which were investigated in vitro. Lam et al [9] indicated a contribution of different metal catalysts that was contained in the materials, resulting in the pulmonary disturbances. In contrast to their study, the only containing metal was iron in all of materials used here, and the amount of iron contained is shown in the Table 1 . We did not find any significant correlation between the amount of iron and T-cell responses. Thus, a metal catalysts reported by Lim et al [7] may be a minor factor in T-cells responses to CNTs in vivo as shown in the present study. However, this possibility remains to be clarified in the future study. Cui et al [26] showed that SWNTs inhibited human embryo kidney cell proliferation and decreased cell adhesive ability for the aim of exploring SWNTs biocompatibility. Shvedova et al [27] indicated that exposure of human epidermal keratinocytes to SWNTs produced oxidative stress and cellular toxicity, as indicated by the formation of free radicals, accumulation of peroxidative products, antioxidant depletion, and loss of cell viability after $18 \mathrm{~h}$ of SWNTs exposure in vitro. Additionally, exposure to SWNTs resulted in ultra-structural and morphological changes in cultured cells.

Their results indicate that unrefined SWNTs exposure can result in accelerated oxidative stress and may produce dermal toxicity in exposed workers. Additionally, Monteiro-Riviere et al [28] reported a toxicity of MWNTs on human epidermal keratinocytes in vitro culture, suggesting that chemically unmodified MWNTs were present within cytoplasmic vacuoles of the keratinocytes at all fime points. The MWNTs also induced the release of the proinfiammatory cytokine such as IL8 from 
cells, resulting in irritation response on the skin. When considering the biological response of asbestos, our previous study [8] revealed a markedly low value of $\mathrm{CD}^{+} / \mathrm{CD}^{+}$and severe inflammatory aspects with giant cells after subcutaneously asbestos-implantation for one month in mice (Fig. 14). Thus, it is sure that the biological response of CNTs demonstrated here is significantly lower than that of asbestos.

Finally, an examination of T-cells in peripheral blood can suggest the effective tool for inspecting the workers health when workers may be accidentally exposed by CNTs dusts. 


\section{Figure captions}

Figure 1 (a) FE-SEM images and (b) HR-TEM images of single walled carbon nanotubes (see insert is a schematic model); it is noteworthy that SWNTs are self-assembled into larger bundle structure. (c) FE-SEM image and (d) HR-TEM image of multi-walled carbon nanotubes with diameter of ca. 20nm; typical amorphous carbon nanotubes exhibits small sized fringes are roughly aligned along the length direction. (e) FE-SEM image and (f) HR-TEM image of multi-walled carbon nanotubes with diameter of ca. $80 \mathrm{~nm}$; highly crystalline nanotubes exhibit highly developed graphene layers. (g) FE-SEM image and (h) TEM image of cup-stacked type carbon nanofibers; tilted graphene layers are stacked along the tube length (insert is a schematic model).

Figure 2 Time-dependent changes in body weight of subcutaneously carbon nanotube-implanted animals. It is noteworthy that no large variation is observed.

Figure 3 Time-dependent changes in (a) $\mathrm{CD} 4^{+}$, (b) $\mathrm{CD}^{+}$and (c) $\mathrm{CD} 4^{+} / \mathrm{CD} 8^{+}$after the subcutaneous implantation of SWNTs. Asterisks indicate statistically significant difference $(\mathrm{P}<0.05)$ versus control..

Figure 4 Light microscopic images of SWNTs-implanted skin tissue at 1, 2, 3 weeks and 1 month at different magnifications $($ left panel $\times 40$, right panel $\times 200$ ).

Figure 5 Time-dependent changes in (a) $\mathrm{CD}^{+}$, (b) $\mathrm{CD}^{+}$and (c) $\mathrm{CD} 4^{+} / \mathrm{CD} 8^{+}$after the subcutaneous implantation of MWNTs-I. Asterisks indicate statistically significant 
difference $(\mathrm{P}<0.05)$ versus control.

Figure 6 Light microscopic images of MWNTs-I implanted skin tissue at 1, 2, 3 weeks and 1 month at different magnifications (left panel $\times 40$, right panel $\times 200$ ).

Figure 7 Time-dependent changes in (a) $\mathrm{CD}^{+}$, (b) $\mathrm{CD} 8^{+}$and (c) $\mathrm{CD} 4^{+} / \mathrm{CD} 8^{+}$after the subcutaneous implantation of MWNTs-II. Asterisks indicate statistically significant difference $(\mathrm{P}<0.05)$ versus control.

Figure 8 Light microscopic images of MWNTs-II implanted skin tissue at 1, 2, 3 weeks and 1 month at different magnifications (left panel $\times 40$, right panel $\times 200$ ).

Figure 9 Time-dependent changes in (a) $\mathrm{CD}^{+}$, (b) $\mathrm{CD}^{+}$and (c) $\mathrm{CD} 4^{+} / \mathrm{CD}^{+}$after the subcutaneous implantation of cup-stacked type carbon nanotubes. Asterisks indicate statistically significant difference $(\mathrm{P}<0.05)$ versus control.

Figure 10 Light microscopic images of CSNTs-implanted skin tissue at 1, 2, 3 weeks and 1 month at different magnifications (left panel $\times 40$, right panel $\times 200$ ).

Figure 11 High magnification $(\times 400)$ light microscopic images of skin tissue (stained by Mac-3 antibody) after one-week implantation; (a) control, (b) SWNTs, (c) MWNTs-I, (d) MWNTs-II, and (e) CSNTs.

Figure 12 High magnification $(\times 400)$ light microscopic images of skin tissue (stained 
by Mac-3 antibody) after one month implantation; (a) control, (b) SWNTs, (c) MWNTs-I, (d) MWNTs-II, and (e) CSNTs.

Figure 13 Light microscopic pictures of skin tissue (stained by HE) after 3 months implantation at different magnifications ( $\times 40$ and $\times 200)$; (a) and (b) SWNTs, (c) and (d) MWNTs-I, (e) and (f) MWNTs-II, (g) and (h) CSNTs.

Fig 14 Light microscope pictures of asbestos implanted skin tissues ((d), (e) and (f)) versus control ((a), (b) and (c)) after one-month implantation at three different magnifications. 


\section{References}

[1] Dresselhaus MS, Dresselhaus G, Eklund PC. Science of fullerenes and carbon nanotubes. Academic Press:San Diego. 1996:756-864.

[2] Oberlin A, Endo M, Koyama T. Filamentous growth of carbon through benzene decomposition. J Crys Grow 1976; 32:335-349.

[3] Endo M, Kim YA, Hayashi T, Nishimura K, Matusita T, Miyashita K, et al. Vapor-grown carbon fibers (VGCFs): Basic properties and their battery application. Carbon 2001; 39:1287-1297.

[4] Endo M, Koyama S, Matsuda Y, Hayashi T, Kim YA. Thrombogenicity and blood coagulation of a microcatheter prepared from carbon nanotube-nylon-based composite. Nano Letters 2005; 5:101-105.

[5] Endo M, Shikata M. Growth of vapor-grown carbon fibers using fluid ultra-fine particles of metals. Japanese Journal of Applied Physics 1985;54(5): 507-510.

[6] Endo M. Grow carbon fibers in the vapor phase. Chem Tech 1988; 18:568-576.

[7] Donaldson K, Tran CL. An introduction to the short-term toxicology of respirable industrial fibres. Mutation Research 2004;557: 5-9.

[8] Koyama S, Tanaka S, Yamaguchi Y, Haniu H, Takeichi T, Konishi G, et al. Different tissue reactions to activated carbon fibers-pathological and immunological findings after subcutaneous implantation. Mol Cryst Liq Cryst 2002;388:167-171.

[9] Lam CW, Junes JT, McCluskey R, Hunter RL. Pulmonary toxicity of single-wall carbon nanotubes in mice 7 days after intratracheal instillation. Toxicological Science 2004;77: 126-134.

[10] Warheit DB, Laurence BR, Reed KL, Roach DH, Reynolds GAM, Webb TR. 
Comparative Pulmonary Toxicity Assessment of Single-wall Carbon Nanotubes in Rats. Toxicological Sciences 2004;77:117-125.

[11] Shvedova AA, Castranova V, Kisin ER, Schwegler-Berry D, Murray AR, Gandelsman VZ, et al. Exposure to carbon nanotube material: assessment of nanotube cytotoxicity using human keratinocytes cells. J Toxicol Environ Health A 2003;66: 1909-1926.

[12] Robert F. Nanomateirals show signs of toxicity. Science 2003;300: 243.

[13] Mattson MP, Hadooon RC, Rao AM. Molecular functionalization of carbon nanotubes and use as substrates for neuronal growth. J Mol Neurosci 2001;14: 175-182.

[14] Marynard AD, Baron OPA., Foley M, Shvedova AA, Kisin ER, Castranova V. Exposure to carbon nanotube material: Aerosol release during the handling of unrefined single-wall nanotube material. J Toxicol Emviron Health A 2004;67: 87-107.

[15] Movat HZ. Inflammation, Immunity and Hypersensitivity-Cellular and Molecular Mechanisms. Harper \& Row Publishers, New York, 1978.

[16]Endo M, Hayashi T, Kim YA, Muramatu H, Ezaka M, Watts PCP, et al. The possible route to large-scale production of SWNTs through combinational techniques of substrate and floating Methods. J Nanos Nanotec 2004; 4 (1/2): 132-135.

[17]Endo M, Kim YA, Hong SH, Matushita T, Takeda T, Hayashi T, et al. Structural characterization of carbon nanofibers obtained by hydrocarbon pyrolysis. Carbon 2001; 39: 2003-2010.

[18]Kim YA, Hayashi T, Endo M, Kaburagi Y, Tsukada T, Shan J, et al. Synthesis and structural characterization of thin multi-walled carbon nanotubes with a partially 
facetted cross section by a floating reactant method. Carbon 2005; In press.

[19]Endo M, Kim YA, Fukai T, Hayashi T, Oshida K, Terrones M, et al. Structural characterization of cup-stacked type nanofibers with an entire hollow core. Appl Phys Lett 2002; 80 (7): 1267-1269.

[20]Tao F, Gonzalez-Flecha B, Kobzik L. Reactive oxygen species in pulmonary inflammation by ambient particulates. Free Rad Bio \& Med 2003;35:327-340.

[21] McNamara A, Williams DF. The response to the intramuscular implantation of pure metals. Biomaterials 1981;2:33-40.

[22] Tsien M, Morris D, Pietruska J, Jian K, Kane A, Hurt R. Health impacts of carbon nanomaterials: role of iron residues in cellular toxicity and DNA damage. Extended Abstract, Carbon conference 2005. Kyeongju (Korea), American Carbon Society; 2005.

[23]Rosenberg AS, Mizuochi T, Sharrow SO, Singer A. Phenotype, specificity, and function of $\mathrm{T}$ cell subsets and $\mathrm{T}$ cell interactions involved in skin allograft rejection. $\mathrm{J}$ Exp Med 1987;165: 1296-1315.

[24] Sprent J, Schaefer M, Lo D, Komgold R. Properties of purified T cell subsets: II. In vivo responses to class I vs. class II H-2 differences. J Exp Med 1986;163: 998-1011.

[25] Kalish RS, Morimoto C, Schlossman SF. Generation of T8 (CD8 ${ }^{+}$) cytotoxic cells has a peferential requirement for $\mathrm{T}^{+} 2 \mathrm{H}^{-}$inducer cells. Cell Immunol 1988; 111 : 379-389.

[26]Cui D, Tian D, Ozkan CS, Wang M, Gao H. Effect of single wall carbon nanotubes on human HEK293 cells. Toxicology Letters 2005;155:73-85.

[27] Shvedova AA, Castranova V, Kisin ER, Schwegler-Berry D, Murray AR, Gandelsman VZ, et al. Exposure to carbon nanotube material: assessment of 
nanotube cytotoxicity using human keratinocyte cells. J Toxicol Environ Health A 2003;66: 1909-1926.

[28] Monteiro-Riviere NA, Nemanich RJ, Inman AO, Wang YY, Riviere JE. Multi-walled carbon nanotube interactions with human epidermal keratinocytes. Toxicology Letters 2005;155:377-384. 


\begin{tabular}{|c|c|c|c|c|}
\hline I.D. & SWNTs & MWNTs-I & MWNTs-II & $\begin{array}{l}\text { Cup-stacked } \\
\text { CNT }\end{array}$ \\
\hline Diameter $(\mathrm{nm})^{(\mathrm{a})}$ & $0.8-2.2 \mathrm{~nm}$ & $\begin{array}{l}10-50 \mathrm{~nm} \\
(\text { Ave. }=20 \mathrm{~nm})\end{array}$ & $\begin{array}{l}50-150 \mathrm{~nm} \\
(\text { Ave. }=80 \mathrm{~nm})\end{array}$ & $\begin{array}{l}50-150 \mathrm{~nm} \\
(\text { Ave. }=80 \mathrm{~nm})\end{array}$ \\
\hline Length $(\mu \mathrm{m})^{(\mathrm{a})}$ & - & $10-20 \mu \mathrm{m}$ & $10-20 \mu \mathrm{m}$ & Up to $100 \mu \mathrm{m}$ \\
\hline $\mathrm{d}_{002}(\AA)^{(\mathrm{b})}$ & - & 3.48 & 3.389 & 3.3985 \\
\hline $\begin{array}{l}\text { Specific surface area } \\
\left(\mathrm{m}^{2} / \mathrm{g}\right)^{(\mathrm{c})}\end{array}$ & 641 & 56 & 18 & 50 \\
\hline Real density $\left(\mathrm{g} / \mathrm{cm}^{3}\right)^{(\mathrm{d})}$ & - & 1.78 & 2.08 & - \\
\hline R value $\left(\mathrm{I}_{\mathrm{D}} / \mathrm{I}_{\mathrm{G}}\right)^{(\mathrm{e})}$ & 0.002 & 0.8545 & 0.1342 & 0.7832 \\
\hline Iron content $^{(\mathrm{f})}$ & $1-1.5$ wt. $\%$ & $3-5$ wt. $\%$ & Below 300ppm & $1 \mathrm{wt} \%$ \\
\hline Post-treatment $^{(\mathrm{g})}$ & None & None & $\mathrm{HTT}=2800^{\circ} \mathrm{C}$ & None \\
\hline
\end{tabular}

${ }^{(a)}$ Diameter and length of multi-walled carbon nanotubes are determined by FE-SEM observation while diameter of SWNTs is determined by radial breathing mode (RBM) from Raman.

${ }^{(b)} \mathrm{d}_{(002)}$ is interlayer spacing from an XRD pattern.

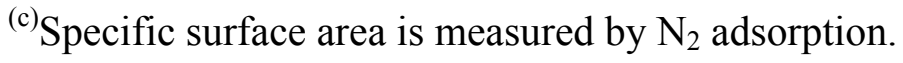

${ }^{(\mathrm{d})}$ Real density is measured by a pycnometer.

${ }^{(e)} \mathrm{R}$ value is the intensity of the $\mathrm{D}$ band divided by the intensity of the $\mathrm{G}$ band from Raman spectra.

${ }^{(\mathrm{f})}$ Iron contents were measured by atomic absorption spectroscopy.

${ }^{(g)}$ Heat treatment in argon atmosphere is applied in order to improved structural perfection accompanying with the removal of defect and also metal particles. 
Table 2 Classification of biological response patterns of $\mathrm{CD}^{+}$and $\mathrm{CD} 8^{+}$

\begin{tabular}{|c|c|c|c|c|}
\hline Sample I. D. & 1 week & 2 weeks & 3 weeks & 3 months \\
\hline \multirow{2}{*}{ SWNTs } & $\mathrm{CD}^{+}(-) \mathrm{CD}^{+}(\downarrow)$ & $\mathrm{CD}^{+}(\uparrow) \mathrm{CD}^{+}(-)$ & $\mathrm{CD}^{+}(-) \mathrm{CD}^{+}(\downarrow)$ & $\mathrm{CD}^{+}(\uparrow) \mathrm{CD}^{+}(\uparrow)$ \\
\hline & $\mathrm{CD}^{+} / \mathrm{CD}^{+}(\uparrow)$ & $\mathrm{CD}^{+} / \mathrm{CD}^{+}(\uparrow)$ & $\mathrm{CD}^{+} / \mathrm{CD}^{+}(\uparrow)$ & $\mathrm{CD}^{+} / \mathrm{CD}^{+}(-)$ \\
\hline \multirow{2}{*}{ MWNTs-I } & $\mathrm{CD}^{+}(\downarrow) \mathrm{CD}^{+}(\downarrow)$ & $\mathrm{CD}^{+}(\uparrow) \mathrm{CD}^{+}(-)$ & $\mathrm{CD}^{+}(-) \mathrm{CD}^{+}(\downarrow)$ & $\mathrm{CD}^{+}(-) \mathrm{CD}^{+}(-)$ \\
\hline & $\mathrm{CD}^{+} / \mathrm{CD}^{+}(-)$ & $\mathrm{CD}^{+} / \mathrm{CD}^{+}(\uparrow)$ & $\mathrm{CD} 4^{+} / \mathrm{CD}^{+}(\uparrow)$ & $\mathrm{CD}^{+} / \mathrm{CD}^{+}(-)$ \\
\hline \multirow{2}{*}{ MWNTs-II } & $\mathrm{CD}^{+}(\downarrow) \mathrm{CD}^{+}(\downarrow)$ & $\mathrm{CD}^{+}(\uparrow) \mathrm{CD}^{+}(-)$ & $\mathrm{CD}^{+}(\downarrow) \mathrm{CD}^{+}(\downarrow)$ & $\mathrm{CD}^{+}(\uparrow) \mathrm{CD}^{+}(\uparrow)$ \\
\hline & $\mathrm{CD}^{+} / \mathrm{CD}^{+}(-)$ & $\mathrm{CD}^{+} / \mathrm{CD}^{+}(\uparrow)$ & $\mathrm{CD} 4^{+} / \mathrm{CD}^{+}(-)$ & $\mathrm{CD}^{+} / \mathrm{CD}^{+}(-)$ \\
\hline \multirow{2}{*}{ CSNTs } & $\mathrm{CD}^{+}(\downarrow) \mathrm{CD}^{+}(\downarrow)$ & $\mathrm{CD}^{+}(\uparrow) \mathrm{CD}^{+}(-)$ & $\mathrm{CD}^{+}(-) \mathrm{CD}^{+}(\downarrow)$ & $\mathrm{CD}^{+}(\uparrow) \mathrm{CD}^{+}(-)$ \\
\hline & $\mathrm{CD} 4^{+} / \mathrm{CD}^{+}(-)$ & $\mathrm{CD}^{+} / \mathrm{CD}^{+}(\uparrow)$ & $\mathrm{CD} 4^{+} / \mathrm{CD} 8^{+}(\uparrow)$ & $\mathrm{CD}^{+} / \mathrm{CD}^{+}(\uparrow)$ \\
\hline
\end{tabular}

